E ISSN : $2252-4797$

Volume 9 - No.2 2020

ournal Polingua

Scientific Journal of Linguistics, Literature and Education

\title{
Imroving English University Students’ Speaking Skill Through Effortless English Movie Technique
}

\author{
Salmi Tri Apriani ${ }^{1,}$ Dian Purnama Sari ${ }^{2}$ \\ ${ }^{1,2}$ SekolahTinggi Bahasa Asing Prayoga, Padang, 25115, Indonesia \\ E-mail:1 asalmitri@yahoo.com,2dian@stba-prayoga.ac.id
}

\begin{abstract}
The aim of this article was to explain how to implement Effortless English Movie Technique in order to improve students' English speaking skill. Effortless English Movie is a six-day implementation technique that has different instructions for each day. It was a library research since the data are taken by gathering information from books and journals. However, the researchers also did pre-liminary observation to see the students' perception toward the learning technique at university level to get a better comprehension about the real situation in learning process. The researchers, then, adapted the theory of the Effortless English Movie by A.J. Hoge with the real situation, so it can be used by the teachers well into their classrooms. This technique leads learners to focus on listening to be familiar with English conversation or dialogue, and continue to the speaking section to practice their pronunciation with the movie that has been chosen by the teacher. By using repetition strategy to practice the speaking skill, this technique focuses on speaking like a native speaker with an amusing way. Therefore, Effortless English Movie Technique is an optional easy and enjoyable technique that helps students a lot in learning to communicate fluently and accurately. The researchers hope that this article is useful for the readers, students, teachers, and next researchers in giving information about improving speaking skill. The researchers also expect that this technique can be one of the most favorite techniques that teachers use in classroom for English lesson, especially speaking skill.
\end{abstract}

Keywords — Speaking Skill; Effortless English Movie Technique

\section{INTRODUCTION}

Speaking is one of the four-skills of a language that involves oral communication in expressing or delivering information, thought, and feeling. If people do not speak or give oral communication, they will not be able to interact with other people. This skill has numerous reasons why learners have to pay attention to. The first one is speaking as a tool for communication. Based on Reference [7], in doing things people need to speak up to make it happen. In other words, speaking skill becomes a bridge to communicate with other. The other opinion comes from Reference [2] which says speaking skill is beneficial for career enhancement. Because employers have always valued the ability to speak well, they always try to improve this skill to their career development.

Even though speaking seems like a customary skill of language, because it is oral communication, this skill is still the hardest one to be mastered. Reference [6] stated that speaking is the most difficult one than other skills because it happens in real time and cannot be edited or revise such in writing. It is also mentioned that people in
Asia spend their time from high school until university to be able to talk in English fluently because most of them do not have oral ability even they want to learn willingly [8].

Based on the preliminary observation did by the researchers to English majored students, it was found that speaking was one of skills that they cannot master well, even though at the beginning they thought it was quite easy. It happened because they have less confident to speak English in front of their friend. Their less confidence and lack of practice make them could not have good speaking skill, as well as pronunciation. Nevertheless, as English students they did hope to be able to speak fluent like native speaker. It is also proved that speaking is also difficult because it is the skill where learners cannot evaluate themselves from the other English skills and components such as listening, writing, reading, grammar, vocabulary and pronunciation [5] .

Watching movie can be a new technique to improve students' spoken English. Many learners prefer enjoyable activities which make them feel comfortable in learning. Effortless English movie is one of the ways that can apply movies as a new technique to improve speaking 
skill. This technique is focus on speaking like a native speaker by using repetition strategy to practice the speaking skill with an amusing way. This technique will help English students to improve their speaking ability without forgetting accuracy of the sentence. In conclusion, speaking is a skill that must be mastered to help students communicate easily and get in touch with other people. Even speaking is not as easy as people think; students can still improve their speaking ability by Effortless English movie technique. At the end, students, especially English majored students, will be able to speak fluently and accurately.

\section{Effortless English Movie Technique}

This technique was launched on August $26^{\text {th }} 2015$ by Allen J. Hoge, a researcher who was rising from a lowpaid English teacher to become the leader of an international education company. He was also described as The World's \#1 English Trainer and the \#1 Best Teacher of English according to Effortless English web page. The Effortless English movie technique, as described in AJ's book, is a powerful technique for completely mastering the vocabulary, phrases, grammar, and pronunciation which are in movies. In using this technique, learners study and practice each scene of a movie- learning it deeply before moving on to the next scene. The goal of the movie technique is to learn deeply, so pupils never forget what they have learned.

The key of this technique is repetition. This technique lasts about a week for a scene of a movie. It focus on sentences with same of mimic from native speaker. Learners, then, need to take their time to pay attention more on the native's accent, gesture, and emotion. Therefore, it should make them speak English accurately and fluently.

\section{II.}

\section{METHOD}

This research used library research whose information was got from books and journals. Before collecting the data, the researchers did a preliminary observation to Prayoga School of Foreign Language students, where the second researcher teach, to sum up researchers' opinion for this article. The researchers chose 2 random students from each semester to be asked about their opinion toward speaking English. The interview questions were in form of open ended question which asked about their speaking ability, their difficulties in speaking, and their personal interest about learning English from media like song and movie.

\section{RESULTS AND DISCUSSION}

\section{Implementation of Effortless English Movie Technique}

The creator of this technique, A.J. Hoge, explains that this technique is not just about sitting down and watching the movie, but also involves learners to watch movie as one of enjoyable technique to improve speaking skill. The learners who want to improve their speaking with this technique must follow some major instructions which spend many days in applying it. To get the best result in doing this technique, learners must follow each rules and steps of this technique without skipping any instruction for better speaking.

Before doing this technique, there are some considerations which learners need to know. The first one is to choose the best type of movie to watch. Learners can choose all genres of movie as they want, but for the best result of practicing, learners must watch modern movies. It means that the movie has time setting which is in the present, not a movie that is about past period time such as history movies. It is because that kind of movie does not use the daily English conversation style that people use right now.

Another consideration is to avoid certain kind of comedy movies. Comedy movies give jokes that sometimes hard to be understood by non-English speakers. The jokes cannot be understood by the learners because sometimes the actors mock about the culture or politic, so it will be difficult for non-English speakers to understand about the movies.

The last reason is to do the technique every day in row. To get the best result for this technique, learners must pass this technique every day without forgetting any step which is instructed. They must follow all the instruction in everyday step. Hence, they must not forget to do any given instruction in each day because this technique needs an intensive time to be done.

Some instructions to implement this technique in order to improve their speaking skill are divided into six days that has different steps for each day. Learners must not forget to do this technique six days in row without passing any day that will be instructed below to get the best result in improving their speaking skill. Learners firstly have to watch the whole movie that has been chosen in order to understand the plot of the movie. They may use their mother tongue subtitle while watching the movie, for example Indonesia people use Indonesian subtitle, or even Minangnese use Minang language subtitle while watching a movie if it is available. This is the introduction step which the learners have to do before doing the first step in implementing Effortless English Movie Technique.

\section{Day 1 Implementing Effortless English Movie Technique}

In day one, the first step learners must do is to watch the first scene, which has length about the first two or three minutes. Learners just need to watch that scene by using English subtitle. When they listen and read along over the subtitle, they have to write down the words which they do not know.

After watching the first scene and writing the unknown words, learners pause the scene. Next, they can use dictionary to look for the meaning from the unknown words. Then, if learners have understood the meaning of the words, they must repeat to watch the first scene. This time, they have to notice the words because they have written them down and known about the meaning. After the first scene ends, pause it again. At this time, the students can review their words lists to make them familiar with the words that become their difficulty before. 
After that, learners have to watch the first scene again like before. Here, learners must remember the meaning of unknown words in the first scene because they have reviewed the words before. They ought to watch the first scene several times to listen more deeply to the actors' pronunciation and the scene context. After repeating the scene, learners can finish for treatment of the first day and continue to the next day action.

\section{Day 2 Implementing Effortless English Movie Technique}

In day two, learners will watch the first scene like before, but now the English subtitle should be off. Learners must watch the whole first scene again and listen carefully to the actors. After watching the first scene, they have to pause it and review the words lists that they had made before. It is for remembering the forgotten phrases or words of the first scene. Now they have to listen very closely to the speech and the conversation speed of the actor. Because learners have listened many times, they should have remembered everything about the first scene. Then, they must listen again the first scene without subtitle. They can watch it for ten times or more on day two which may take about twenty minutes to watch the first scene many times. If they have finished the first scene and remembered all the conversation, it means they have done for the day two.

\section{Day 3 Implementing Effortless English Movie Technique}

Day three is focus on pronunciation because learners have listened many times and understood the context well. Firstly, learners must start from the same scene like before. In that scene, there will be some sentences appear. Pupils have to pause at the first sentence of the first scene. After that, they repeat the sentence the same way as the actor says it, even the pronunciation, gestures, and mimics. Next, learners can continue to the next sentence and do the same. The key of day three is listening carefully to the actor's pronunciation because students must speak as close as the actor's emotion and intonation. They must imitate the actor's voice many times as possible to make it better.

\section{Day 4 Implementing Effortless English Movie Technique}

In this day, learners will do shadowing technique. Shadowing in this technique is watching a scene without pausing and try to speak as same as the actors' line. Learners should try to utter the conversation in loud voice at the same time with the actor. They will be actually left behind with the actor, but they should keep trying to pronounce it as fast as the actors. English subtitle may be turned on to help them to know the line of the conversation. For day four, learners just need to play the scene, shadow like the actor, and rewind the scene.

Day 5 Implementing Effortless English Movie
Technique

In day five the learners will do it deeper than previous days. They can begin the section by playing the first scene, without subtitle. After that, they will shadow the lines with the same intonation, emotion, mimic, voice, action or move and pronunciation as the actor does. Everything must be same like the actor. It means that learners will do this technique correctly and carefully. They will hear the actor first and start speaking like him without reading subtitle, so they can be more focus on their speaking.

\section{Day 6 Implementing Effortless English Movie Technique}

Day six is an optional step for the learners to do. Learners will do shadowing again, but they must record while shadowing. Students can listen and compare how close they are with the actor's pronunciation. They will notice the different pronunciation and take a note to improve it. Finally, learners can go to the next scene with the same technique.

On the other hand, the researchers suggest learners have to do this step at the end of their practice in order to evaluate their mispronunciation or other mistakes. That is why the sixth day step should become a must because it will help the pupils to evaluate their speaking mistakes. In brief, every step on Effortless English Movie Technique can be figured as below.

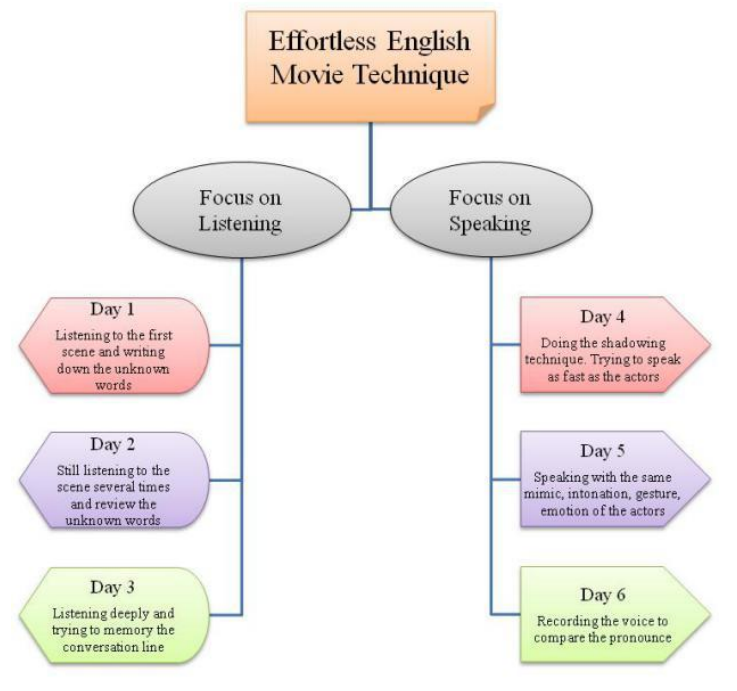

Fig. 1 Steps to Implement Effortless English Movie Technique.

Even this technique lasts for six days for watching a scene of movies, it can be still done in school or campus with a more simple way and shorter time. One thing that students need to understand is Effortless English Movie can be practiced every time and everywhere, not just at school. It means that learners can apply this technique as self-study at home without helping from teachers or others. If teachers are interested in applying this technique in their subject, the researchers has arranged an easier implementation for implying this in class. This implementation stands for four steps which are preparation, pre-teaching, whilst teaching, and post-teaching.

Preparation is a step where teachers need to provide some equipment before implementing this 
technique in class. First thing that teachers need to do is to download a movie, complete with English subtitle. The movie must be suitable with students' ages and proper to show at school. After that, teachers type the line or dialogue of the scene and print it as many as the students. Teachers should prepare the script because it is more effective to save time than letting the students write it down by themselves while teaching. Finally, the last thing teachers need to prepare is projector and sound system to support the learning process.

In brief, this technique is focus on listening, imitating, speaking and practicing. This technique is a sixday implementation that uses movies as media for learning. Even students need a lot of time to do this technique, it still can be done in one day at school. This technique does not require teacher because it can be a self-learning process to master English. If all equipmentis ready to be used, teachers can start the technique from pre-teaching step as explained below.

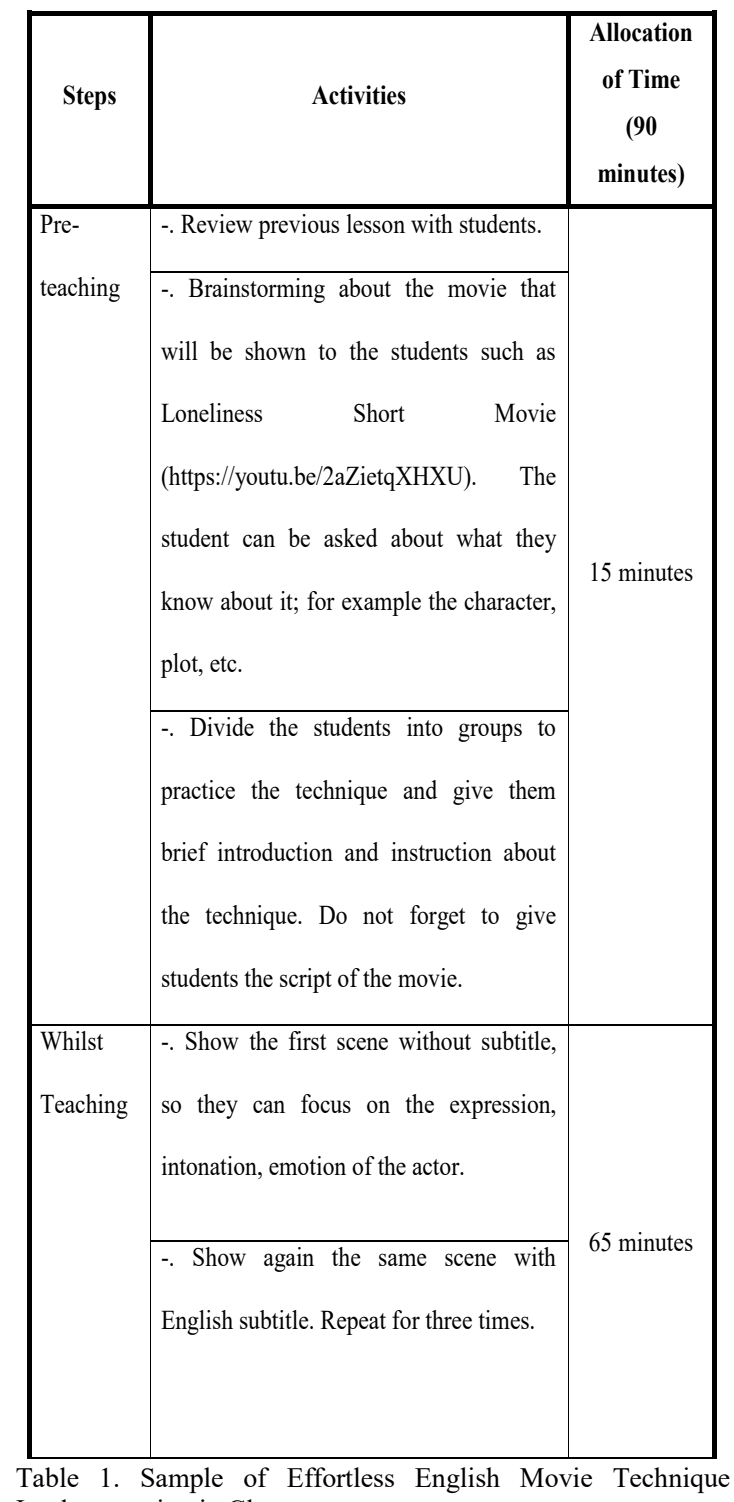

Implementation in Class

\section{Advantages and Disadvantages of Effortless English Movie Technique}

As explained in his YouTube video, Allen. J. Hoge told that this technique brings a lot of improvement in listening and speaking of the learners. It is because the learners in the beginning have listened carefully to do this technique. They are trained to listen more and notice some details of actors' pronunciation such as intonation, speed, and accent.

Moreover, learners' speaking will be much faster, more natural, more fluent, and clearer accent after doing this technique. It is because the learners have knowledge about how to speak properly, in the beginning of technique. After having some crucial points about speaking correctly, they will try to speak as accurate as the actors do. They challenge themselves to consider some aspects in imitating the actors such as the intonation, gesture, mimic, accent, and speed of the speech. On the other words, pupils will be more aware in their speaking because they have got an understanding about the important aspects which must be included in speaking fluently and correctly.

Afterwards, learners will have a huge improvement in vocabulary and spoken grammar. It can be seen clearly when the learners write the unknown words from the scene at the beginning of this technique. After that, they often review the list of words that becomes familiar in their mind because they also see dictionary to find out about the meaning of the words which make them notice the words more than before. About the spoken grammar, the learners get it from the actors' conversation. Almost every line of conversation uses correct grammar because the script is written and spoken by native speaker of English.

The next advantages that researchers found are the right emotion and intonation. Intonation is the rise and fall of the voice in speaking while emotion is a feeling which can be caused by a situation. When learners hear high or deep voice that must be imitated, it can be said as intonation. In this aspect, students must understand the context of the line or conversation. If the context tries to narrate something, actors usually start with deep voice. In addition, when the actors' line is asking a question, they usually give higher pitch or tension on the context. It means that, the students also study the pattern of sentence or kind of speaking indirectly.Furthermore, if learners have a conversation or dialogue with other, they will need appropriate feeling in speaking. The right way to confess suitable emotion is by watching movies which show learners directly the emotion of the actors in speaking.

Other advantage of this technique is the accent which is aspirated by the natives. Accent in every movie can be different one to another. The actors of the movies can be British, American, Africa-America, or even Australian which all of them have a characteristic way in talking. In this case, students will try to follow the actors' accent in the movie. Then, it would make the speaking itself sound like a native speaker. The accent that learners use can give a huge impact to their speaking because they will sound like a student who has good pronunciation and proper accent.

Hence, the students are aware with grammatical sound. Pupils who try and pay attention deeply with the 
actors' pronunciation will realize some grammatical rules that can appear in the line or words. For example the use of plural noun, students usually forget to speak it clearly. After doing this technique, they will notice the grammar more and pronounce it clearer than they did before. Unfortunately, Effortless English Movie Technique also has disadvantages to be applied. This technique spends a lot of time to be finished. For one movie, it can last almost three months or even more. However, this technique is more focus on improving, not studying the language or pronunciation. That is why time is not really a big deal in this technique because it is just about the improvement in the speaking skill.

In conclusion, there are varied advantages which are shown based on the creator himself and the researchers. The advantages really fulfill the entire vital aspect components of speaking. Then, the disadvantage does not always seem as a shortage because the time is not the focus of this technique. In other words, this technique will help learners in improving their speaking skill through six-day implementation technique with several certain rules in it.

\section{CONCLUSION}

Effortless English Movie technique is a six-day implementation technique that is focus on mastering grammar, vocabulary, listening, pronunciation, and speaking. This technique provides different instructions for each day, the first three days for listening and the last three days for speaking. This technique offers a lot of advantages such as changes in the way learners talk, accent, spoken grammar, and also intonation. Even there are several advantages in this technique, it still has a disadvantage that is spend a lot of time.

From the previous discussion, it can be concluded that speaking is one of the essential skill which must be mastered by English students. Many difficulties revealed in mastering this skill such as vocabulary, or unable to revise what learners say to others. Luckily, movie can be the media to improve speaking skill, but learners need a technique that implies movies as learning process.

At the end, Effortless English Movie Technique can be a new inovation which can be used to improve students' speaking skill. It is because this technique is really amusing and be able to change the way pupils talk in English to be much better.

\section{ACKNOWLEDGMENT}

We would like to thank lectures and students in STBA Prayoga Padang for the participation and knowledge to complete this article.

\section{REFERENCES}

[1] Abbaspour, F. (2016). Speaking Competence and Its Components: A Review of Literature. International Journal of Research in Linguistics, Language Teaching and Testing, 1(4), (2016) p. 144 152.

[2] Gerald, Gillis. (2013). The Importance of Speaking Skill. [Online]. Available: $\quad$ http://www.geraldgillis.com/importance-speakingskills/.p. 1

[3] Hoge, Allen. J. How To Improve English Speaking Skills. . [Online]. Available: https://effortlessenglishclub.com/improve-englishspeaking-skills. (2018)

[4] ILAC. (2018). 10 Tips For Improving Your English Speaking Skills. [Online]. Available: https://www.ilac.com/10-tips-for-improvingyour-english-speaking-skills/

[5] Lorena, C., \& Sadiku, M. The Importance of Four Skills Reading, Speaking, Writing, Listening in a Lesson Hour. European Journal of Language and Literature Studies, 1(1), (2015). P.29-31.

[6] Nunan, David. Task based Language Teaching. Cambridge: Canbridge University Press. (2004). p.48.

[7] Qureshi, I. A.. The Importance of Speaking Skill for EFL Learners, 2013. p2-3.

[8] Shiyong, P. Analysis of Perceived Difficulty Rank of English Skills of College Students in China, 8(3), 15-21. [Online]. Available: https://doi.org/10.3968/5128. (2014).

[9] Wil. 10 Top Tips For Improving Your Spoken English. [Online]. Available :https://englishlive.ef.com/blog/language-lab/10-top-tipsimproving-spoken-english/. (2016). 